\title{
Les autotraduccions poètiques al castellà de Joan Fuster (Verbo, 1946-1949)
}

\author{
[Joan Fuster's poetics self-translations into spanish \\ (Verbo, 1946-1949)]
}

\author{
Salvador Ortells Miralles \\ Universitat de València \\ espaijoanfuster@espaijoanfuster.org
}

\begin{abstract}
Resum: Es pretén posar en relleu la importància de la poesia i la traducció en el conjunt de l'obra literària de Joan Fuster a partir de les autotraduccions poètiques en castellà que publicà, entre 1946 i 1949, en Verbo, revista literària que fundà i dirigí amb José Albi. Partint d'una contextualització prèvia en què es justifica la presència de l'autotraducció en la història de la literatura catalana, s'analitzen els motius pels quals Fuster hagué de traduir un nombre considerable de poemes. En aquest sentit, hi intervenen dos factors bàsics que determinen l'orientació de la nostra investigació: el paper central de Fuster en la creació de Verbo i els dubtes que generaren les autotraduccions poètiques respecte a la tria lingüística de Fuster en els seus inicis poètics, dubtes que hem tractat d'esbrinar a partir de la correspondència inèdita entre Fuster i Albi.
\end{abstract}

Paraules Clau: Joan Fuster, José Albi, poesia, traducció, autotraducció, literatura comparada, revista literària Verbo

Aвstract: This article tries to remark the importance of the poetry and the translation in the collection of Joan Fuster's literary work from the poetic self-translations in Spanish that he published, between 1946 and 1949, in Verbo, the literary review he founded ran with José Albi. Based on a previous contextualization in which we justify the presence of self-translation in the history of Catalan literature, we analyse the reasons why Fuster had to translate a big amount of poems. In this respect, two factors come into play in the direction of our research: Fuster's main role in the creation of Verbo and the doubts that the poetic self-translations caused as for Fuster's linguistic choice in his poetic beginnings, doubts that we have tried to find out from the unpublished correspondence between Fuster and Albi.

KeYwords: Joan Fuster, José Albi, poetry, translation, self-translation, comparative literature, literary review Verbo

Recepció: 03/08/20I7. Acceptació: I I/o9/20I7. Publicació: I 5/I2/20I7

REVISTA VALENCIANA DE FILOLOGIA / I (20I7) p. I99-222/ISSN 055 6-705X / DOI I0.28939/RVF.VIII.27 


\section{Introducció}

Si tenim en compte que l'assaig és, amb diferència, el gènere literari més rellevant en l'obra de Joan Fuster, no hauria d'estranyar-nos que la seua poesia i les seues traduccions siguen dues de les parcel-les que menys atenció han rebut per part dels estudiosos. No obstant això, val a dir que compten amb aportacions parcials valuoses que han contribuït a posar en relleu aspectes bàsics del pensament fusterià. A tall d'exemple, destaquem el capítol que Josep Ballester (1990: 71-82) dedica a la presència de la ironia en la seua poesia en l'estudi Joan Fuster: una aventura lírica, i el text preliminar de Francesc Pérez i Moragón (2014: 8-58) a la versió i adaptació que féu Joan Fuster, el 1952, de L'Annonce faite à Marie, del dramaturg francés Paul Claudel. Siga com siga, la curta perspectiva que atorguen els vint-i-cinc anys del traspàs de l'escriptor de Sueca, fa pensar que la seua poesia i les seues traduccions seguiran despertant un interés limitat entre els qui s'apropen als seus escrits. Malgrat tot, poemaris com Escrit per al silenci i Ofici de difunt o les traduccions al català de les novel-les d'Albert Camus ${ }^{1}$ haurien de suscitar, al nostre parer, un interés major. En aquesta direcció apunta el present article, que, en abordar les autotraduccions poètiques al castellà que publicà en la revista Verbo, reivindica, per partida doble, el Fuster poeta i traductor.

Potser el lector es preguntarà per què Fuster traduí, del català al castellà, un nombre considerable dels seus primers poemes, i no, posem per cas, El descrèdit de la realitat o El País Valenciano, ambdós llibres traduïts per Josep Palàcios al castellà i al català respectivament? Certament, la pregunta és pertinent si tenim en compte que Fuster només exercí l'autotraducció en els poemes publicats en Verbo. Abans, però, de tractar de respondre l'interrogant plantejat, convé reflexionar sobre la freqüència amb què els escriptors en català han traduit, i segueixen traduint, les seues pròpies creacions a altres idiomes. En l'article «Más allá de la traducción: la autotraducción», la professora Maria Recuenco

1 D’Albert Camus, Fuster va traduir en solitari La pesta (1962), i en col-laboració amb Josep Palàcios, El mite de Sísif (1965), L'exili i el regne (1967), L'home revoltat (1986) i L'estrany (1989).

REVISTA VALENCIANA DE FILOLOGIA / I (20I7) p. I99-222 SALVADOR ORTELLS MIRALLES

Les autotraduccions poètiques al castellà de Joan Fuster ('Verbo', 1946-1949) / 200 
(2011: 194) rebat l'afirmació de l'escriptor Eduardo Mendoza segons la qual l'autotraducció és una pràctica literària marginal, tan sols amb una presència massiva en certes societats plurilingües, com ara la catalana, en què constitueix el pas d'una llengua minoritària — i sovint minoritzada- a la llengua estatal dominant en el mercat editorial. En efecte, segons indica Rainier Grutman (2009: 127), l'autotraducció és una forma de contacte entre literatures de variable prestigi i estatus que genera, en molts casos, una relació asimètrica, tot i que sempre ha gaudit d'una llarga tradició en el món literari, al marge de les circumstàncies de la societat en què té lloc. En aquest sentit, són ben nombrosos els escriptors de diferents procedències geogràfiques i lingüístiques que, per raons diverses, decidiren traduir algunes de les seues obres. Entre els casos més estudiats en les darreres dècades, remarquem, sense voluntat exhaustiva, els noms de Samuel Beckett, Vladimir Nabokov, Czeslaw Milosz, Isak Dinesen, Milan Kundera i Joseph Brodsky. Així mateix, en la història de la literatura catalana, no han estat pocs els escriptors que han practicat, en major o menor mesura, l'autotraducció. De fet, Ramon Llull fou un dels autotraductors més importants de l'edat mitjana europea —amb una obra ingent en català, llatí i àrab- $i$, vuit segles després, continuen la tradició autors contemporanis com Pere Gimferrer, Carme Riera, Valentí Puig, Joan Francesc Mira, Joan Margarit, Josep Piera, Narcís Comadira i Feliu Formosa. No hi ha dubte, doncs, que l'autotraducció ha estat i està present en la literatura catalana des de l'època fundacional fins a l'actualitat.

Ara bé, caldria preguntar-se si el motiu que empenyia Ramon Llull a traduir, del català a l'àrab, el Libre del gentil e dels tres savis era el mateix que quan Carme Riera traduïa, del català al castellà, Dins el darrer blau. Tots dos autors pretenien, és cert, arribar a un públic determinat, però les motivacions apologètiques lul-lianes res tenen a veure amb les de la novel-lista Carme Riera. Fet i fet, com apunta Rainier Grutman, són moltes les variables que intervenen en la decisió d'un escriptor a l'hora de traduir-se:

Many [writers] decide to cross the Rubicon of self-translation, either because they are utterly dissatisfied with existing translations of their work,

REVISTA VALENCIANA DE FILOLOGIA / I (20I7) p. I99-222 SALVADOR ORTELLS MIRALLES

Les autotraduccions poètiques al castellà de Joan Fuster ('Verbo', 1946-1949) / $20 \mathrm{I}$ 
or because they cannot find a publisher for the first version, or because it was poorly received (even censored) in the initial language. Prompted by circumstances, in other words, and comforted by their own bilingualism, they basically try their hand at translation (Grutman 2013: 193).

Òbviament, Fuster no travessà el Rubicó de l'autotraducció perquè estiguera descontent amb traduccions prèvies dels seus poemes, ja que ningú no els havia traduït a cap llengua. D'altra banda, tampoc no tenia excessius problemes per a publicar els seus poemes, en català, en la premsa valenciana, a pesar de les restriccions que el franquisme imposava a la literatura autòctona durant la postguerra. ${ }^{2}$ Així ho demostren els setze poemes, de temàtica i mètrica diverses, que publicà entre 1945 i 1948 en l'Almanaque de Las Provincias i les revistes Víspera, Esclat i Pensat $i$ Fet. Hem de recórrer a la carta de l'11 de juliol de 1948 que Fuster envià al poeta Xavier Casp per a trobar una justificació estrictament lingüística, tècnica, sobre l'autotraducció quan afirma que:

Coneixent el castellà com el coneixem, resulta molt més pràctic que siga el propi autor qui faça la traducció, perquè triarà sempre les paraules castellanes amb el mateix criteri poètic que va triar les valencianes, $\mathrm{i}$ aquelles seran sempre molt més escaients que no les correspondències literals (Fuster 2006: 79).

El criteri adduït, reiterem, és lingüístic. És a dir, justifica l'operació, però no n'explica el motiu que l'engega. Tornem, de nou, al punt de partida, a la pre-

2 La situació del català al País Valencià de postguerra no oferia possibilitats als escriptors que es resistien a acceptar les imposicions del franquisme. Les representacions públiques del català quedaren reduïdes a les manifestacions populars i folklòriques dels llibrets de falla i de les revistes falleres, és a dir, a mostres literàries escadusseres i d'una periodicitat tan variable que eren incapaces de fidelitzar un públic lector ampli. Si exceptuem l'Almanaque de Las Provincias, que publicava anualment un nombre reduit de poemes i articles, a penes existien plataformes que serviren de base a una literatura deslligada del populisme de les associacions col-laboracionistes amb el règim franquista. Fins que la Diputació Provincial de València no creà el 1948 la Institució Alfons el Magnànim, i Xavier Casp i Miquel Adlert posaren en marxa un any després la col·lecció "L'Espiga», de l'editorial Torre, els escriptors valencians no comptaren amb editorials consistents. També existia la via clandestina d'edicions sufragades per mecenes valencianistes, però era una opció marginal.

REVISTA VALENCIANA DE FILOLOGIA / I (20I7) p. I99-222

SALVADOR ORTELLS MIRALLES

Les autotraduccions poètiques al castellà de Joan Fuster ('Verbo', 1946-1949) / 202 
gunta inicial: què empeny realment Fuster a traduir els seus poemes al castellà? La resposta requereix prendre en consideració dos factors bàsics: en primer lloc, el paper imprescindible de Fuster en la creació de Verbo, i, en segon lloc, la censura del català imposada pel director de la revista, José Albi, que està directament relacionada amb la nebulosa que plana sobre la tria lingüística de Fuster en els seus inicis poètics, una nebulosa que, en la mesura possible, tractarem de dissipar.

\section{Joan Fuster i la creació de Verbo}

No es pot concebre la creació de la revista Verbo sense fer esment a l'amistat de joventut de Joan Fuster i José Albi. Fou amb motiu de la designació del pare d'Albi com a secretari de l'Ajuntament de Sueca, abans de la Guerra d'Espanya, que la seua família s'instal-là al número 10 del carrer de Sant Josep, al pis de dalt de la casa on vivia Joan Fuster. Veïns i alhora amics, estudiaren el batxillerat a l'Acadèmia Politècnica de Sueca, compartiren les primeres lectures i somiaren diversos projectes literaris en comú. Malauradament, amb l'arribada de la Guerra d'Espanya el 1936, la família Albi s'hagué de traslladar forçosament a Cadis i la relació s'interrompé fins que acabà el conflicte bèl-lic i pogueren reprendre el contacte. Així recordava Albi el retrobament amb el seu amic:

El reencuentro en Sueca, una vez finalizada la contienda, va descubriendo las primeras afinidades que crean la base de una sólida, aunque ingenuamente definida, identificación, especialmente en el terreno literario que, en torno a nuestros 17 años de edad, nos deslumbraba, aunque las motivaciones y las primeras ideas se nos ofrecían difusas. Sentíamos la ambición o, mejor, la ilusión de crear, de hacer cosas. [...] Pero para nosotros lo verdaderamente importante era nuestro proyecto de revista. Soñábamos en la poesía. Nos atraía de un modo especial el cine. Y la música (Albi 1993: 280).

L'anhelat retrobament, però, no va durar gaire perquè la família d'Albi hagué de fer les maletes de nou i marxar, ara cap a Bilbao. Dos anys van trans-

REVISTA VALENCIANA DE FILOLOGIA / I (20I7) p. I99-222

SALVADOR ORTELLS MIRALLES

Les autotraduccions poètiques al castellà de Joan Fuster ('Verbo', 1946-1949) / 203 
córrer fins que s'instal-laren de manera definitiva a Alacant. No obstant això, la relació amical dels joves no es trencà en cap moment, ni tampoc el projecte de la revista, que esdevingué un tema recurrent de la seua correspondència, segons afirma Albi:

Se adensó en tamaño, y pienso que en interés, nuestra correspondencia sobre temas de la cultura en general y, de manera especial, sobre el proyecto de nuestra revista, que ya empezaba a vislumbrarse como posible sobre la base de pequeños apoyos económicos. Esto sucedía en torno a la mitad de la década de los 40 . Nos reunimos en Valencia y trazamos ya las líneas ingenuamente concretas de nuestra publicación. Ahora, cuando lo pienso me da la sensación de que estábamos deseando crear algo así como una pequeña isla para nuestro uso personal. No había acuerdo en el título, y acabamos tomando el camino de en medio; el más cómodo, el menos comprometido: Cuadernos Literarios (Albi 1993: 281).

En efecte, corroborem la importància que cobra el projecte de la revista, encara en un estat embrionari, en diverses cartes anteriors a la publicació del primer número. El fragment que reproduïm, pertanyent a la carta que Albi envià a Fuster des de Bilbao el 16 de juny de 1944, és una mostra de l'entusiasme que havien dipositat en l'empresa:

Tienes razón, ahora podría cuajar nuestra revistilla poética. ¿Por qué no intentarlo? Si tú dices que hay gente y afición podría prosperar nuestra idea con feliz éxito. Ya sé que siempre peco de optimista, pero peor es lo contrario. El problema es el dinero, ya lo sé, pero con un poco de buena voluntad todo se arreglaría. [...] ¿ ¿No recuerdas el presupuesto que nos hicieron en la imprenta cuando intentamos sacar a la luz aquella nuestra primitiva revista? Si te sientes con ánimo para la empresa, yo encantadísimo; se podría hacer algo que estuviera bien (Albi 1944: s. p.).

Albi i Fuster projectaren diverses aventures literàries que no quallaren, excepte el somni juvenil de la revista, que començà a créixer a passos agegantats amb l'establiment dels Albi a Alacant. Tanmateix, durant el procés de gestació

REVISTA VALENCIANA DE FILOLOGIA / I (20I7) p. I99-222

SALVADOR ORTELLS MIRALLES

Les autotraduccions poètiques al castellà de Joan Fuster ('Verbo', 1946-1949) / 204 
hagueren de véncer múltiples obstacles administratius, com queda reflectit en la carta del 20 de desembre de 1945 en què el desànim sembla apoderar-se d'Albi: «Y ahora volvamos a nuestra tantas veces proyectada revista: hablé con el encargado de la imprenta de la Diputación: el coste de la impresión de la revista sería mínimo, pero dice que no se atreven a hacer nada sin permisos, censuras y demás adminículos» (Albi 1945: s. p.). Gràcies a la determinació dels dos joves $i$, sobretot, als contactes del pare d'Albi, aconseguiren evitar tots els entrebancs que sorgien al pas. Per fi, a l'inici de 1946, albiraren l'horitzó desitjat i tan sols quedava ultimar-ne els detalls. En aquest sentit, la carta del 18 de gener de 1946 que Albi envià a Fuster és simptomàtica dels dubtes precedents a la publicació de la revista, dubtes sobre el títol, la tècnica d'impressió, els mínims de qualitat exigibles als col-laboradors i un llarg etcètera de qüestions que palesen la barreja d'il-lusió i de presses d'última hora que devia envair-los:

Querido Fuster: Como podrás observar, en cuanto a mi pereza en escribir, es mayor el ruido que las nueces. Te contesto casi a vuelta de correo, pues hace tan sólo dos días que recibí tu carta. Lo hago, sobre todo, por el asunto de nuestra revistilla, a la que parece que, por fin, le ha llegado su hora. De nuevo hay grandes posibilidades de que pueda salir impresa. Mañana lo sabré seguro. De todas formas, bien sea a molde, bien sea a multicopista, con la cubierta impresa, como tú me dices, saldrá el primer número en los primeros días de Febrero [...] Claro que, sobre todo si sale impresa, hay que sostener un cierto nivel literario, ni que decir tiene que nada extraordinario, pero sí, al menos, decoroso. Por eso creo que debías retocar y corregir aquellas cosas que te parezcan un poco incorrectas o vulgares; claro que con el permiso de los interesados. [...] El título es lo que está más verde, quedamos en llamarla Mar, pero tiene esa palabra una eufonía que me huele mal. Cuando alguien la escuche algo desprevenido, puede sufrir la lamentable equivocación de ponerse firme, y eso sería terrible. De todas formas a falta de pan... ya sabes. Si tú encuentras algo mejor, proponlo, aunque ha de ser todo rápido. ¿Qué te parece un subtítulo? Algo así como Revista poética o Revista literaria (Albi 1946a: s. p.).

REVISTA VALENCIANA DE FILOLOGIA / I (20I7) p. I99-222 SALVADOR ORTELLS MIRALLES

Les autotraduccions poètiques al castellà de Joan Fuster ('Verbo', 1946-1949) / 205 
Només uns dies després, Albi tornà a enviar una altra carta a Fuster, datada el 23 de gener de 1946, per a mantenir-lo al corrent de la resolució definitiva dels entrebancs més importants que havien retardat la revista. Constatem de nou la importància vital de les maniobres burocràtiques que hagué de realitzar el pare d'Albi en qualitat de secretari de la Diputació d'Alacant. La carta posseeix un valor documental considerable, atés que permet conéixer els requisits que exigia la censura per a autoritzar la publicació d'una revista literària:

Ha hablado mi padre con el que se encarga aquí en Alicante de la censura, y le ha dicho que el permiso para una revista es difícil de obtener, pero que podemos hacerlo con tal que no mencionemos que se trata de una "revista periódica", y que sería conveniente que no numerásemos tampoco. De esa forma nuestra publicación podrá considerarse como una serie de folletos, y en ese caso es él mismo el que tiene atribuciones para censurarla. Así es que por fin tendremos revista impresa; mejor que mejor (Albi 1946b: s. p.).

Però l'afany repressor de la censura franquista no es detenia en aspectes externs i accessoris de la revista, sinó que també coartava la llibertat a l'hora de triar un aspecte tan determinant com el títol. ${ }^{3}$ En la mateixa carta que acabem de reproduir, comprovem l'actuació del censor sobre la qüestió: «Sobre el título dijo el buen señor de que te hablo, que sería más conveniente poner "algo que no suene excesivamente a revista": Cuadernos Literarios o Cuadernos de Literatura.» (Albi 1946b: s. p). Vençudes, per fi, les dificultats inicials, el primer número aparegué en març de 1946 després d'un camí d'incerteses que Albi resumia, dos anys després, en l'editorial del número de novembre-desembre de 1948:

Verbo nació tras una larga gestación que duró tres, o tal vez, cuatro años. Fue allá por 1941, en Valencia. Sus protagonistas: José Albi y

3 Segons hem pogut comprovar en la carta del 18 de gener de 1946, el títol acordat per Fuster i Albi per a la revista era Mar, tot i que es veieren obligats a canviar-lo per la censura, que proposava el títol asèptic de Cuadernos Literarios.

REVISTA VALENCIANA DE FILOLOGIA / I (20I7) p. I99-222

SALVADOR ORTELLS MIRALLES

Les autotraduccions poètiques al castellà de Joan Fuster ('Verbo', 1946-1949) / 206 
Joan Fuster. La vocación y el entusiasmo fueron levantando proyecto tras proyecto que la realidad fue tumbando uno tras otro. Pero no hubo desaliento. Pasaron los años y se separaron los amigos. Fuster continuó en Valencia y Albi fue a caer a Alicante. Allí surgió la oportunidad cuando ya menos confiaban: facilidades de impresión, facilidades económicas... Y así nacieron, en Marzo y en Abril-Mayo de 1946 los dos primeros números de Cuadernos Literarios. La pequeña revista, en espíritu y contenido apuntaba hacia Valencia. No tenía — como nunca ha tenidode alicantina, otra cosa que el pie de imprenta sobre el que se apoyaba. Como era natural se iniciaron relaciones con algunos elementos locales a los que se le pidió colaboración. Cuadernos Literarios aumentaron sus páginas y modificaron su título: Verbo-Cuadernos Literarios se llamaron a partir de agosto del mismo año. En el número que apareció ese mes seguía como único director José Albi. Este quiso organizar más tarde una especie de Consejo de Dirección en el que figuraron varios nombres. Pero surgieron diferencias y Albi y Fuster volvieron a monopolizar su revista. Hoy Verbo sigue dirigido, encauzado y animado por sus mismos fundadores (Albi 1948a: s. p.).

Tot seguit oferim la versió dels fets de Fuster, que a penes difereix de la d'Albi, però aporta matisos interessants:

La història de Verbo és molt senzilla. Vaig estudiar amb Pepe Albi al batxillerat. El seu pare era un personatge fabulós. Em va aconsellar una vegada: «Juanito, has de llegir un llibre cada dia», i tant m'ho vaig creure que estic fent-ho encara. El cas és que un dia l'Albi i jo vam decidir de fer una revista literària, amb el conegut problema dels diners, d'autoritzacions, etc. i tot això només va ser possible quan el senyor Albi pare va ser secretari de la Diputació Provincial. Primer editàrem 2 o 3 números que es titulaven Cuadernos literarios. Després, el senyor Albi fill, que vivia a Alacant, va entrar en relació amb el senyor [Vicente] Ramos i Manolo Molina, un poeta que va ser molt amic de Miguel Hernández i que, com aquest, era també un xicot admirable, d'aquells eixits de la terra o d'on siga, que tenien una gran expressió en la seua llengua. [...] Total que amb tot això vam anar fent aquells Cuadernos literarios amb

REVISTA VALENCIANA DE FILOLOGIA / I (20I7) p. I99-222 SALVADOR ORTELLS MIRALLES

Les autotraduccions poètiques al castellà de Joan Fuster ('Verbo', 1946-1949) / 207 
un nou nom ignominiós: Verbo. A mi això de Verbo sempre m'ha semblat un títol ridícul, com de revista de gramàtica, una cosa per l'estil, però és igual.

I mira, vam fer, en definitiva, unes coses, no crec que siguen extraordinàries, però sí que n'hi hagué una de la qual estic content: per iniciativa de l'Albi, vam fer una antologia del surrealisme espanyol en uns anys en què el surrealisme era una cosa nefasta i prohibida... El problema és: què és —o què era- el surrealisme? $\mathrm{O}$ millor dit, què pensaven uns desgraciats de províncies sobre el surrealisme, quan ni Barcelona, que era un món molt estrany per a nosaltres, ni Madrid no havien tret massa sobre el tema. Total: vam fer, en definitiva, la primera antologia del surrealisme, tot i que a hores d'ara em qüestione com a surrealisme alguns dels noms o poemes que vam incloure. I la revista va funcionar uns quants anys fins que ens vam cansar de fer-la (Fuster 2003: 273-274).

La majoria dels col·laboradors dels primers números o bé havien nascut a Sueca, com ara Lluís Granell, Francesc de Paula Burguera, Justo Cuadrado o el mateix Fuster, o bé mantenien contactes al poble, com era el cas d'Albi. Era, per tant, una revista que, si més no en els inicis, donava a conéixer les primeres creacions literàries del cercle d'amistats suecanes de Fuster. Amb aquesta nòmina inicial de joves escriptors, i d'altres que anaren incorporant-se, Verbo es va convertir en una de les revistes valencianes més prestigioses. En aquest sentit, Jaume Pérez Montaner indica amb encert l'actitud crítica i mancada de prejudicis academicistes dels impulsors:

Enfront a la increible mediocritat de l'«oligarquia intel-lectual»valenciana —en frase de Fuster-, destaca l'ambició literària dels joves promotors de Verbo [...] Si més no, suposen una visió de la literatura, i de la literatura espanyola en particular, des de la perifèria; practiquen una escriptura que en alguns moments s'enfronta als criteris artístics oficialistes, o en viu al marge (Pérez Montaner 1992: 275).

El que, en principi, podia semblar una aventura literària de joventut, va prendre cos fins a esdevenir un projecte ambiciós, rigorós i ben organitzat.

REVISTA VALENCIANA DE FILOLOGIA / I (20I7) p. I99-222 SALVADOR ORTELLS MIRALLES

Les autotraduccions poètiques al castellà de Joan Fuster ('Verbo', 1946-1949) / 208 
L'afany regenerador d'Albi i de Fuster fou clau per a introduir continguts nous, sempre amb la mirada orientada — en la mesura del que era possible - a tot el que es coïa culturalment a l'altra banda dels Pirineus, sense oblidar la necessitat de dinamitzar els nous valors de les literatures peninsulars, i amb una atenció constant a la creació en català per part de Fuster:

En el trist panorama cultural de la postguerra, Verbo pretenia erigir-se en un lloc d'encontre i recepció de les avantguardes estètiques de l'època: el realisme social, l'existencialisme i, molt particularment, el surrealisme. El punt de referència, i també la font d'alguns articles, traduïts pel mateix Fuster, són les revistes literàries franceses: L'Arche, Fontaine, La Nef, Poésie, Confluences, Les Temps Modernes, Poètes prisonniers, Esprit, Revue de Paris, Pyrénées i Europe, segons la relació de títols que Albi comunica a Fuster haver rebut l'estiu de 1947. Àvids lectors i crítics, els dos amics i codirectors teoritzen, pontifiquen i encasellen estèticament els autors, de vegades, com ara Gerardo Diego, en contra de l'apreciació dels mateixos interessats.

Verbo es publicava en castellà i s'ocupava preferentment de literatura castellana, però les seues pàgines acolliren notícies i comentaris sobre la creació en català i fins i tot originals en aquesta llengua

(Furió 1994: 60-61).

Bona prova de l'ambició i l'habilitat dels directors de Verbo és que aconseguiren publicar textos d'escriptors de prestigi internacional, com ara Rainer Maria Rilke, Franz Kafka, Paul Éluard, Giuseppe Ungaretti o André Gide, però també d'autors rellevants en castellà com Miguel Hernández, Gabriel Celaya o Lezama Lima, a més d'entrevistar figures de la talla de Vicente Aleixandre i de dedicar un monogràfic a Gerardo Diego. I malgrat l'oposició inicial d'Albi, Fuster hi donà cabuda a escriptors valencians i catalans com els germans Xavier i Vicent Casp, Lluís Guarner, Joan Baptista Bertran, Joan Valls, Santiago Bru i Vidal, Francesc de Paula Burguera i Pere Quart, entre altres. Aquestes col-laboracions es combinaven amb cròniques, notícies i ressenyes de llibres $\mathrm{i}$ revistes. Això, pel que fa a la part estrictament literària, perquè, a més, s'hi pu-

REVISTA VALENCIANA DE FILOLOGIA / I (20I7) p. I99-222 SALVADOR ORTELLS MIRALLES

Les autotraduccions poètiques al castellà de Joan Fuster ('Verbo', 1946-1949) / 209 
blicaven nombrosos assaigs sobre cinema i art, i es posaven a l'abast del públic reproduccions d'artistes plàstics contemporanis com Antonio Saura, Giorgio di Chirico, Marc Chagall o Henri Matisse.

$\mathrm{Al}$ capdavall, la revista fou per a Fuster un autèntic banc de proves per a realitzar les primeres incursions literàries, tant en el gènere poètic com en l'assagístic, amb una certa regularitat. I no només això, sinó que també li permeté conéixer a fons els mecanismes interns que regeixen el funcionament d'una publicació periòdica. Cal tenir present que Fuster, a més d'exercir de colllaborador i d'encarregar-se de les tasques de la direcció amb Albi, escrivia ressenyes, articles culturals, notícies d'actualitat literària i, fins i tot, il-lustracions per encàrrec, tal com comprovem en la carta del 16 d'abril de 1948 que li envià Albi: «No vas a tener más remedio que pintar dos o tres dibujitos para la revista. Hay que romper un poco la monotonía de tantas letras. [...] Anda, inspírate y hazlo, y cuanto antes me lo mandes, mejor» (Albi 1948b: s. p.). Així mateix, en la carta del 4 de gener de 1949 Albi li requeria de nou un dibuix per a la coberta d'un poemari de Mercedes Chamorro publicat per la petita editorial associada amb la revista:

Querido Fuster: Dos letras para hacerte rápidamente un encarguito: un encarguito al dibujante así de grande que hay dentro de ti. Se trata de una viñetita para la portada de la señora Mercedes, con un aire primaveral y tal. Se encarece la diligencia y la urgencia, pues es el único requisito que falta para sacar a luz el cuaderno de la dicha joven (Albi 1949a: s. p.).

Tot i això, cal reconéixer que, si bé Fuster era l'home orquestra de la revista, ${ }^{4}$ Albi també constituïa un peça important en l'engranatge. De fet, en

4 A més de signar les col-laboracions com a Joan Fuster, feia servir pseudònims com Jorge F. March, T. Blanch i F. Ortells, o bé signava amb les inicials J. F. o F. O., a fi d'evitar l'aparició reiterada del seu nom. Pel que fa a les editorials, majoritàriament sense signar, Fuster anotava en els seus exemplars de la revista el nom d'Albi per a deixar constància de l'autoria, ja que en molt poques ocasions n'era l'autor. Mireia Ferrando Simon, que en l'actualitat està catalogant els fons hemerogràfic del Centre de Documentació Joan Fuster, està preparant un article en què registra tots els pseudònims emprats en Verbo.

REVISTA VALENCIANA DE FILOLOGIA / I (20I7) p. I99-222

SALVADOR ORTELLS MIRALLES

Les autotraduccions poètiques al castellà de Joan Fuster ('Verbo', 1946-1949) / 2 Io 
la carta que li envià a Fuster el 12 de novembre de 1948 s'observa el ritme tan atrafegat que li imposava la publicació de cada número:

Esta vez no ha sido la pereza la que ha retrasado tanto mi carta. Estoy atareadísimo. Por un lado la revista — de la que ya tengo corregidas las primeras pruebas-; de otro el guion de cine que llevo entre manos, y que pasándolo en limpio me hace perder horas y horas, pues el plazo de entrega termina el último día de este mes; por otro, la Tesis; por otro la fastidiosa correspondencia a que me obliga la revista. (Albi 1948c: s. p.)

En resum, gràcies a l'esforç d'Albi i de Fuster la revista mantingué, des de 1946 fins a 1953, una publicació regular. Fou a partir del número 29, aparegut en desembre de 1954, que cada nova entrega es dilatava en excés. Així, el número 30, del qual se'n va fer una segona versió per a commemorar el desé aniversari de la revista, es publicà en abril de 1956, i el número 31 en la primavera de 1958. A partir de 1963, Fuster se'n desvinculà definitivament, però en Verbo queda recollida, íntegra, la seua producció poètica en castellà. En el quadre següent es consignen els poemes que hi publicà entre març de $1946 \mathrm{i}$ abril de 1949.

Taula 1. Poemes de Joan Fuster publicats en Verbo

\begin{tabular}{|l|l|}
\hline Número & Poemes \\
\hline Març 1946 & $\begin{array}{l}\text { «Poema viII» } \\
\text { «Jardín» } \\
\text { «Noches sin alma» }\end{array}$ \\
\hline Abril-maig 1946 & $\begin{array}{l}\text { «3er poema romántico» } \\
\text { «Poema» } \\
\text { «Poema del suburbio» }\end{array}$ \\
\hline Agost 1946 & $\begin{array}{l}\text { «Dos canciones inacabadas»: } \\
\text { «[Desde mi rincón el cielo esparce...]» } \\
\text { «[Qué corazón tuyo, qué silencio...]» } \\
\text { «Orilla de este amor» }\end{array}$ \\
\hline Octubre-novembre 1946 & «Oda al Mediterráneo» \\
\hline
\end{tabular}

REVISTA VALENCIANA DE FILOLOGIA / I (20I7) p. I99-222

SALVADOR ORTELLS MIRALLES

Les autotraduccions poètiques al castellà de Joan Fuster ('Verbo', 1946-1949) / 2 I I 


\begin{tabular}{|c|c|}
\hline Desembre 1946 & $\begin{array}{l}\text { «Poemas en la Navidad del Señor»: } \\
\text { «Camino de Belén» } \\
\text { «Belén de veras» } \\
\text { «Nochebuena corriente» }\end{array}$ \\
\hline Gener-febrer 1947 & «Presencia de la Muerte» \\
\hline Abril-maig 1948 & $\begin{array}{l}\text { «Tres poemes»: } \\
\text { "A Sant Francesc d'Assís, en llegir el Càntic de les Criatures» } \\
\text { «L'olivera» } \\
\text { «Elegia íntima» }\end{array}$ \\
\hline Novembre-desembre 1948 & «(Conato de imprecación)» \\
\hline Març-abril 1949 & $\begin{array}{l}\text { «Dos poemes»: } \\
\text { «Impressió de tardor» } \\
\text { «Cançó tranquil·la» }\end{array}$ \\
\hline
\end{tabular}

\section{José Albi i la imposició a Joan Fuster de traduir els poemes al castellà}

Contràriament al que calia esperar, la situació d'anormalitat lingüística del català en la postguerra, no dissuadí Fuster a l'hora d'adoptar-lo com a llengua literària en detriment del castellà. Prenia així el camí més genuí, però també, sens dubte, el més treballós. La decisió no fou immediata i no resulta fàcil determinar amb exactitud com i quan optà pel català. De fet, tal com indica Pérez Montaner, abans de donar-se a conéixer en el món literari valencià, Fuster ja havia iniciat un canvi lingüístic profund i ben meditat, un canvi que no fou ràpid i senzill, sinó més aviat complicat i llarg:

Com va canviar de llengua, o de pell, Joan Fuster? És una pregunta que, probablement, ens hem fet molts, de manera especial els valencians de la meua generació $\mathrm{i}$ tots els que bàsicament s'han format durant l'època del franquisme. Com, en un país com el nostre, sense una forta tradició literària en català —caldria retrocedir al segle xv per trobar-la—, sense escoles, sense diaris, sense revistes, sense editorials, sense llibres, en els pitjors moments de la postguerra i en els anys més durs de la dictadura, com, en aquestes difícils circumstàncies, pren partit per la seua llengua, l'estudia i la comença a escriure un jove de Sueca, de Burjassot, o de qualsevol altre indret del País Valencià (Pérez Montaner 1991: 69).

REVISTA VALENCIANA DE FILOLOGIA / I (20I7) p. I99-222 
No menys valuós és el testimoni de l'escriptor i polític Francesc de P. Burguera, atesa la condició d'amic de joventut i veí de Sueca. Des que es van conéixer al principi dels quaranta, Burguera quedà enlluernat aviat per la lucidesa amb què Fuster reflexionava sobre aspectes culturals i històrics de País Valencià, tal com recorda en l'article «Fuster indefugible»:

Em sembla que la preocupació per l'idioma surt, ja, en plena guerra civil —si es vol de manera incipient- com a fruit de l'amistat que Fuster manté amb un altre suecà, Fermí Cortés, company d'estudis de batxillerat i, després, de Facultat de Dret a la Universitat de València. Són tots dos - Fuster i Cortés— els qui, des de Sueca estant, travaran una sincera i perdurable amistat i una comuna preocupació per tot el que suposa la nostra realitat com a poble: culturalment i política. (Burguera 1993: 241-242)

Encara que anà a contracorrent del centralisme franquista que posava en pràctica estratègies per a aniquilar totes les llengües estatals que no foren el castellà, Fuster no elegí una opció lingüística de la nit al matí. Es tracta d'un canvi progressiu arrelat en la constatació diària d'un contrast idiomàtic manifest entre el català, confinat als àmbits privats i domèstics, i el castellà, destinat als àmbits de l'administració, la cultura i l'educació. Amb tot, podem arriscar-nos a datar l'origen del canvi a finals dels anys trenta i principis dels quaranta, en els moments inicials de la instauració del règim franquista. De fet, els primers textos privats de Fuster desvelen un interés creixent per familiaritzar-se amb l'escriptura en català:

Durant el curs 1937-38, quan Fuster tenia quinze anys i Fermí Cortés catorze, ambdós amics s'intercanviaven les històries de Sueca de Joan Baptista Granell i del padre Amado. [...] Les gloses que Fuster va anotar al final d'alguns capítols de la Historia de Granell, crítiques i divertides, testimonien el canvi lingüístic, del castellà al català, que s’havia produï ja en la redacció dels seus papers personals i literaris. [...] També hi contribuiria la lectura dels setmanaris locals, particularment El Sueco i Mosaico,

REVISTA VALENCIANA DE FILOLOGIA / I (20I7) p. I99-222 SALVADOR ORTELLS MIRALLES 
que publicaven col·laboracions en valencià i valencianistes i reproduïen de tant en tant les obres de Bernat i Baldoví (Furió 1994: 37-39).

Es pot objectar que les anotacions a la Historia de Granell pertanyien a un àmbit privat, però el primer text que presentà a un certamen literari, els Jocs Florals de Sueca de 1944, es titulava «Significació espiritual de la Montanyeta dels Sants» i, òbviament, estava escrit en català. Tot i això, no fou el primer text que publicà. Fuster debutà amb «Vint-i-cinc anys de poesia valenciana (19201944)» en l'Almanaque de Las Provincias para 1945. Recorrem a Furió per a establir la cronologia d'ambdós textos:

A Sueca, el grup de joves inquiets perseverava en la seua tasca d'animació cultural. El 21 de setembre de 1944 s'hi celebraren Jocs Florals, els sisens de la història local. [...] Entre els guardonats hi havia, dues vegades, Jacinto Talens, que guanyà el premi del governador civil al tema "Por el Imperio hacia Dios" i el de l'alcalde de València al tema "Significació espiritual de la Montanyeta dels Sants”. Aquest últim, en català, l'havia escrit Fuster, que, potser per l'escrúpol de ser organitzador del certamen i alhora en un gest de subtil ironia, el presentà amb el nom de l'amic, castellanoparlant notori.

"Significació espiritual de la Montanyeta dels Sants", datat el 7 de setembre de 1944 i publicat l'any següent en la memòria dels jocs, és, signat per altre, el "primer" escrit de Joan Fuster. Però el primer a publicar-se, i a dur el seu nom, seria, poc després, "Vint-i-cinc anys de poesia valenciana", aparegut, a finals de 1944, a l'Almanaque de Las Provincias para 1945. Ambdós, escrits en la ratlla dels vint-i-dos anys, adopten ja la forma de l'assaig, literari un i crític l'altre, palesen l'antic interès per la història local i el nou per la literatura valenciana, i usen el català com a vehicle lingüístic (Furió 1994: 54-55).

5 Entre 1944 i 1949, Fuster col-laborà en l'Almanaque de Las Provincias amb un total de dos articles, «Vint-i-cinc anys de poesia valenciana (1920-1944)» i «Subvencionem la literatura», i onze poemes.

REVISTA VALENCIANA DE FILOLOGIA / I (20I7) p. I99-222 SALVADOR ORTELLS MIRALLES

Les autotraduccions poètiques al castellà de Joan Fuster ('Verbo', 1946-1949) / 2 I 4 
Per tant, els primers textos en prosa publicats de Fuster foren escrits en català, i amb una correcció estilística i lingüística notable si considerem l'edat i l'escassesa de referents gramaticals al País Valencià. Però, si ens centrem ara en els primers poemes, observem que també es van publicar en català en l'Almanaque de Las Provincias para 1946, amb data d'octubre de $1945 .{ }^{6}$ Aleshores, per què persisteix una densa nebulosa al voltant de la tria lingüística dels seus inicis. La resposta, en part, cal cercar-la en les afirmacions de José Albi, que tergiversà dades crucials sobre les primeres publicacions de Fuster. Intencionada o no, l'equivocació més rellevant d'Albi fou assegurar que tenia l'«evidència quasi absoluta» que el debut poètic de Fuster es produí en el número inaugural de la revista Verbo, en març de 1946:

El primer número [de Verbo] apareció en Alicante en Marzo de 1946. Se abría con una composición poética de Fuster, escrita en castellano: "Poema viII", y una cita de Rainer María Rilke: "Yo tengo casa entre [el] día y el sueño". Tengo la evidencia casi absoluta de que es su primer poema publicado. Escribe en castellano y, en efecto, se vislumbra en él una evidente huella del poeta alemán (Albi 1993: 281).

No s'entén l'errada d'Albi respecte a la llengua i la data de publicació del primer poema del Fuster si tenim en compte que, en aquells anys, eren companys inseparables d'aventures literàries. I encara menys comprensible és la vehemència amb què manté la tesi segons la qual es va decantar inicialment pel castellà. En aquest sentit, Albi ha estat un dels personatges que més equívocs ha creat al voltant de la tria lingüística de Fuster. Ho corroborem en el mateix article quan afirma que:

Fuster sigue publicando en Verbo poemas escritos en castellano, desde el año 1946 al 1948: diez títulos en total que aparecen firmados con nombre y apellido, y dos bajo el seudónimo de Jorge March. [...] Lo cierto es

6 «Jardí o melangia», «Darrer madrigal» $\mathrm{i}$ «Paisatge» són els poemes que publicà en l'Almanaque de Las Provincias para 1946 amb el títol genèric de «Tres petites elegies».

REVISTA VALENCIANA DE FILOLOGIA / I (20I7) p. I99-222

SALVADOR ORTELLS MIRALLES

Les autotraduccions poètiques al castellà de Joan Fuster ('Verbo', 1946-1949) / 2 I 5 
que en Mayo de 1948, en el número 11 de Verbo publica con el título de “Tres poemes” sus primeros versos valencianos aparecidos en la revista, y que a la vez se reúnen en forma de plaquette (Albi 1993: 281-282). ${ }^{7}$

A més, Albi assenyala l'existència d'un poemari de Fuster en castellà, Barro de siempre, amb el qual es presentà al premi Adonáis de 1947. ${ }^{8}$ Per dissort, en l'actualitat no es conserva cap document del poemari a l'arxiu del Centre de Documentació Joan Fuster. És probable que l'autor el silenciara en no obtenir un resultat positiu, tot i que no disposem de dades que recolzen la hipòtesi. Siga com vulga, i amb el pretext del poemari, Albi aprofitava per a insinuar que la tria lingüística podria haver estat de signe diferent en cas d'haver guanyat el premi referit:

A esto podríamos añadir un dato muy curioso y sin duda revelador del uso del castellano por Fuster en la creación poética, que se nos ofrece en el número 9 de Verbo. Me refiero a la "Relación de poetas presentados al Premio Adonáis 1947”, que se nos entrega por deferencia del Secretario de dicho Concurso, para ser incluida en nuestra revista, y a través de la cual nos enteramos de que Juan Fuster, de Sueca, Valencia, presentó a dicho Premio el libro Barro de siempre. ¿Qué hubiera ocurrido — me pregunto un poco desconcertado- en la trayectoria del escritor, en el caso de haber sido premiado? Yo, poco versado en elucubraciones, y menos en adivinaciones, me limito a expresar mi asombro y quizás también mi preocupación (Albi 1993: 281).

Josep Ballester (2005: 160) també indica l'existència del poemari per a reforçar la tesi dels inicis en castellà de Fuster, però no resulta difícil refutar les

7 Albi s'equivoca quan identifica els «Tres poemes», publicats en el número 11 de Verbo, amb el fascicle 3 poemes, també publicat en la mateixa revista. De fet, els «Tres poemes» inclö̈en les composicions «A Sant Francesc d'Assís, en llegir el Càntic de les Criatures», "L'olivera» i «Elegia íntima», mentre que 3 poemes comprén els poemes «Impressió de tardor», "Aquest crit que ara penso" i "Cançó tranquil·la».

8 La relació de poetes que es presentaren al premi Adonáis en 1947 està detallada en Verbo. Cuadernos Literarios, octubre-novembre de 1947, p. 31-32. El poeta José Hierro en resultà guanyador amb Alegría.

REVISTA VALENCIANA DE FILOLOGIA / I (20I7) p. I99-222

SALVADOR ORTELLS MIRALLES

Les autotraduccions poètiques al castellà de Joan Fuster ('Verbo', 1946-1949) / 2 I6 
paraules d'Albi i de Ballester si llegim el fragment següent de la carta del 26 de setembre de 1947 que Fuster envià a Carles Salvador:

Aquest estiu he acabat dues col-leccions de poemes. Una, amb el títol Alguns poemes menors, composta d'una trentena de sonets, dècimes i romanços. I una altra, titolada [sic] Fang de sempre, uns deu o dotze poemes llargs, en vers lliure. Ja us ho portaré tot, un dia, perquè em doneu la vostra opinió i en feu una censura gramatical: sempre sol escapar-se alguna cosa... (Fuster 1947b: s. p.).

És evident que el poemari fou escrit també en català, però no es pot afirmar amb certesa la llengua en què va escriure la versió original. Ara bé, que realitzara provatures poètiques en castellà no prova en cap cas que era la llengua que emprà sistemàticament en el començament. A més, gràcies a la correspondència amb Albi sabem que Fuster escrivia en català la major part dels poemes de Verbo i que els traduïa a posteriori al castellà per exigència d'aquest. De nou, Albi deixa al descobert les seues reticències sobre la tria lingüística de Fuster en la carta que li envia el 27 de març de $1946:^{9}$

Me pareció una soberana tontería (con todos los respetos) el querer publicar tus poesías como traducciones del valenciano, cuando por sí solas tienen una personalidad y una categoría que hubiesen sido muy rebajadas con la inútil advertencia de la traducción. Son poesías lo suficientemente creciditas para no necesitar apoyos (Albi 1946c: s. p.).

La carta d'Albi, enviada a propòsit de la publicació del primer número de Verbo, demostra que el seu objectiu era silenciar la llengua original dels poemes de Fuster i, en conseqüència, obligar-lo a autotraduir-se. No debades, repetirà idèntiques maniobres fins al número d'abril-maig de 1948 — publicat dos anys després de la creació de la revista- en què, per fi, permetrà la publicació

9 En la carta, Albi fa una breu valoració dels poemes que Fuster publicà en el primer número de Verbo: «Poema VIII», «Jardín» i «Noches sin alma», aquest últim signat amb el pseudònim Jorge F. March.

REVISTA VALENCIANA DE FILOLOGIA / I (20I7) p. I99-222

SALVADOR ORTELLS MIRALLES

Les autotraduccions poètiques al castellà de Joan Fuster ('Verbo', 1946-1949) / 2 I 7 
en català dels poemes de Fuster, acompanyats de les versions en castellà. Mentrestant, Albi seguia fent gala dels seus prejudicis lingüístics i retreia a Fuster la voluntat de deixar constància que els poemes s'havien escrit en català. La carta que li envià el 12 de novembre de 1948 n'és un testimoni més:

Tu «Conato de imprecación» lo he encontrado magnífico. [...] Ya supongo que te figurarás que he suprimido en tu poema todas las monsergas de traducción, fecha, etc. con que rindes tributo de acatamiento a los severos juicios del Patriarca. No puedo explicarme las causas de tu «patriarquitis aguda». Tal vez puedas encontrarla rastreando en las capas más profundas de tu subconsciente. De otra forma no lo comprendo. Si el Patriarca protesta dile que el que se ha declarado en rebeldía he sido yo, no tú (Albi 1948c: s. p.). ${ }^{10}$

Encara uns mesos després, en la carta del 9 d'abril de 1949, ${ }^{11}$ Albi insisteix de nou a Fuster perquè li envie amb urgència les versions en castellà dels poemes en català per al número 15 de Verbo:

Querido Fuster: Me urge mucho que me envíes las versiones castellanas del primero y tercero de tus poemas para publicar en Verbo. El próximo lunes entregaré todos los originales a la imprenta, salvo dos o tres cosas que aún no están listas (Albi 1949b: s. p.).

Per dissort, les actuacions d'Albi, encaminades sempre a eliminar els indicis que testimoniaven la llengua original dels poemes, han induït alguns

10 Aquest fragment de la carta ha estat reproduït per Antoni Furió i Josep Palàcios, que, a més, expliquen el significat de l'expressió "patriarquitis aguda": «El Patriarca era, naturalment, Xavier Casp, al qual se li atribuïa feridorament una ascendència sobre Fuster que potser no arribava a tenir de fet» (Furió i Palàcios 2002: 952-953). El poema al-ludit en la carta, «(Conato de imprecación»), es publicà només en castellà en el número de novembre-desembre de 1948.

11 Aquest fragment està reproduit també en les notes explicatives i materials complementaris del primer volum de l'obra completa de Fuster (Furió i Palàcios 2002: 953), però cal matisar que, encara que Albi es refereix a tres poemes, en el número 15 de Verbo sols es publicaren els poemes «Impressió de tardor» $\mathrm{i}$ "Cançó tranquil·la», junt amb les versions en castellà.

REVISTA VALENCIANA DE FILOLOGIA / I (20I7) p. I99-222

SALVADOR ORTELLS MIRALLES

Les autotraduccions poètiques al castellà de Joan Fuster ('Verbo', 1946-1949) / 2 I 8 
estudiosos a creure que Fuster prioritzava el castellà. Aquest és el cas de Pérez Montaner quan afirma que «els primers poemes que publica els escriu en castellà a Verbo alternant-los amb altres, ja en català, a l'Almanaque de Las Provincias.» (1991: 70). Cal matisar dues inexactituds: en primer lloc, tot i que a partir de 1946 Fuster alterna la publicació de poemes en català i castellà, el debut en català de l'Almanaque de Las Provincias precedeix en quasi un any el debut en castellà de Verbo, i, en segon lloc, si els poemes es publicaven en castellà era per exigència d'Albi. Ara bé, dels poemes publicats en Verbo, sols es pot demostrar documentalment que foren escrits en català els que incloem en el quadre següent. ${ }^{12}$

Taula 2. Procedència dels poemes autotraduïts publicats en Verbo

\begin{tabular}{|c|c|c|}
\hline Poema en castellà & $\begin{array}{l}\text { Data de } \\
\text { publicació }\end{array}$ & Procedència de la versió original en català \\
\hline «Jardín» & Març 1946 & $\begin{array}{l}\text { Publicat dins el conjunt «Tres petites elegies» en } \\
\text { l'Almanaque de Las Provincias para 1946, amb } \\
\text { data d'octubre de 1945. El títol original era } \\
\text { "Jardí o melangia». }\end{array}$ \\
\hline $\begin{array}{l}\text { «[Desde mi rincón el cielo } \\
\text { esparce...]», inclòs en «Dos } \\
\text { canciones inacabadas» }\end{array}$ & Agost 1946 & $\begin{array}{l}\text { Publicat, el 1946, dins el conjunt "Alguns poemes } \\
\text { menors» en l'Almanaque de Las Provincias para } \\
\text { 1947. El títol original era "Cançó inacabada». }\end{array}$ \\
\hline $\begin{array}{l}\text { "QQué corazón tuyo, qué } \\
\text { silencio...]", inclòs en «Dos } \\
\text { canciones inacabadas» }\end{array}$ & Agost 1946 & $\begin{array}{l}\text { Versió en català inèdita titulada «[Quin cor teu, } \\
\text { quin silenci...]». Es conserva còpia mecanoscrita } \\
\text { sense data a l'arxiu del Centre de Documentació } \\
\text { Joan Fuster. }\end{array}$ \\
\hline «Presencia de la Muerte» & $\begin{array}{l}\text { Gener-febrer } \\
1947\end{array}$ & $\begin{array}{l}\text { Versió en català inèdita titulada «La presència } \\
\text { persistent». Es conserva còpia mecanoscrita, amb } \\
\text { data de } 1945 \text {, a l'arxiu del Centre de Documenta- } \\
\text { ció Joan Fuster. }\end{array}$ \\
\hline $\begin{array}{l}\text { "A Sant Francesc d’Assís, en } \\
\text { llegir el Càntic de les Criatures», } \\
\text { «Lolivera» i «Elegia íntima», } \\
\text { inclosos en «Tres poemes» }\end{array}$ & $\begin{array}{l}\text { Abril-maig } \\
1948\end{array}$ & $\begin{array}{l}\text { Publicats en Verbo en versió bilingüe català- } \\
\text { castellà. Fuster signa la versió castellana amb les } \\
\text { inicials V. T. M. }\end{array}$ \\
\hline
\end{tabular}

12 En la primera columna figuren els poemes publicats en castellà; en la segona, la data de publicació en Verbo; i en la tercera, la font que permet comprovar l'existència de la versió catalana.

REVISTA VALENCIANA DE FILOLOGIA / I (20I7) p. I99-222

SALVADOR ORTELLS MIRALLES

Les autotraduccions poètiques al castellà de Joan Fuster ('Verbo', 1946-1949) / 2 I9 


\begin{tabular}{|l|l|l|}
\hline $\begin{array}{l}\text { «Cançó tranquil·la» i } \\
\text { «Impressió de tardor», dins } \\
\text { «Dos poemes» }\end{array}$ & $\begin{array}{l}\text { Març-abril } \\
1949\end{array}$ & $\begin{array}{l}\text { Publicats en Verbo en versió bilingüe català- } \\
\text { castellà. }\end{array}$ \\
\cline { 2 - 3 } & Agost 1949 & $\begin{array}{l}\text { Publicats en versió catalana en el fascicle } \\
3 \text { poemes (1949), d'Ediciones Verbo. }\end{array}$ \\
\hline
\end{tabular}

La resta dels poemes de Verbo — «Poema VIII», «Noches sin alma», «3er poema romántico», «Poema» [Así, / con las horas hundiéndose en mis ojos... »], «Poema del suburbio», "Oda al Mediterráneo», ${ }^{13}$ "Poemas en la Navidad del Señor» ${ }^{14} \mathrm{i}$ "(Conato de imprecación)»- ${ }^{15}$ no podem garantir documentalment que els va escriure en català, atés que caldria disposar dels originals tramesos a Albi. ${ }^{16}$ Tanmateix, si a la correspondència mostrada d'Albi i Fuster, hi afegim els poemes publicats en català en l'Almanaque de Las Provincias i les revistes Vispera, Esclat i Pensat $i$ Fet, i els poemes inèdits en català, datats entre 1945 i 1946, que es conserven a l'arxiu del Centre de Documentació Joan Fuster, observem que els dubtes sobre la tria lingüística de Joan Fuster en els inicis poètics no tenen consistència, ja que el català fou la llengua predominant.

13 No disposem de documents que permeten afirmar que l' «Oda al Mediterráneo», publicada en el número d'octubre-novembre de 1946 de Verbo, fou escrita en català, ja que la "Quasi-oda al Mediterrani», inclosa en el poemari Terra en la boca (1953), tot i estar datada també en 1946, no deixa de ser una reformulació de l' «Oda al Mediterráneo».

14 Aquest conjunt de poemes presenta dubtes al voltant de la llengua original d'escriptura per la dificultat de mantenir l'equivalència en el còmput sil-làbic i en la rima d'uns poemes que, en uns casos, tenen una extensió considerable, i en altres, responen a una composició mètrica concreta, com ara el sonet.

15 Malgrat que no es conserva cap document del poema escrit en català, en sabem de la seua existència per la carta del 12 de novembre de 1948 que Albi envià a Fuster.

16 Ens ha estat impossible disposar de la correspondència enviada per Fuster a Albi. En paraules d'Albi, les cartes es feren malbé accidentalment: «Quedaban en mi poder misivas tan divertidamente festivas e hilarantes (Fuster, en eso, como en tantas otras cosas, era genial), como la que me envió escrita en una larga tira de papel higiénico de más de un metro de larga. Se trataba de un interminable, descacharrante, aunque intencionadísimo y divertidamente maligno poema, en octosílabos asonantados, que desapareció, junto con casi un centenar de cartas suyas, en uno de esos odiosos cambios de casa, en esta ocasión pasado por agua; y ya se sabe que la relación lluvia-papel resulta irremisiblemente incompatible.» (Albi 1993: 285).

REVISTA VALENCIANA DE FILOLOGIA / I (20I7) p. I99-222

SALVADOR ORTELLS MIRALLES

Les autotraduccions poètiques al castellà de Joan Fuster ('Verbo', 1946-1949) / 220 


\section{Bibliografia}

Albi, J. (1944) [Carta manuscrita de José Albi a Joan Fuster del 16 de juny de 1944], Centre de Documentació Joan Fuster, AJFO.

- (1945) [Carta manuscrita de José Albi a Joan Fuster del 20 de desembre de 1945], Centre de Documentació Joan Fuster, AJFO.

- (1946a) [Carta mecanoscrita de José Albi a Joan Fuster del 18 de gener de 1946], Centre de Documentació Joan Fuster, AJFO.

_ (1946b) [Carta mecanoscrita de José Albi a Joan Fuster del 23 de gener de 1946], Centre de Documentació Joan Fuster, AJFO.

- (1946c) [Carta mecanoscrita de José Albi a Joan Fuster del 27 de març de 1946], Centre de Documentació Joan Fuster, AJFO.

- (1948a) «Una pequeña historia de Verbo. Especialmente dedicada a Salvador Pérez-Valiente», Verbo. Cuadernos Literarios, novembre-desembre, s. p. [editorial].

(1948b) [Carta mecanoscrita de José Albi a Joan Fuster del 16 d'abril de 1948], Centre de Documentació Joan Fuster, AJFO.

- (1948c) [Carta mecanoscrita de José Albi a Joan Fuster del 12 de novembre de 1948], Centre de Documentació Joan Fuster, AJFO.

- (1949a) [Carta manuscrita de José Albi a Joan Fuster del 4 de gener de 1949], Centre de Documentació Joan Fuster, AJFO.

- (1949b) [Carta manuscrita de José Albi a Joan Fuster del 9 d'abril de 1949], Centre de Documentació Joan Fuster, AJFO.

(1993) «Joan Fuster: adolescencia y amistad», dins Antoni Martí (ed.): Fuster entre nosaltres, València, Conselleria de Cultura de la Generalitat Valenciana, p. 279-286.

Ballester, J. (1990) Joan Fuster: una aventura lírica, València, Tres i Quatre.

- (2005) «Entre eriçó i guineu. Joan Fuster i el grup Torre. A propòsit de la correspondència amb Xavier Casp, Miquel Adlert i Santiago Bru», L’Espill, 21, p. 158-174.

Burguera, F. (1993) «Fuster indefugible», dins Antoni Martí (ed.): Fuster entre nosaltres, València, Conselleria de Cultura de la Generalitat Valenciana, p. 241-246.

Fuster, J. (1946) «Poema viıı», Cuadernos literarios, març, s. p.

(1946a) «Jardín», Cuadernos literarios, març, s. p.

(1946b) «Noches sin alma», signat amb el pseudònim Jorge F. March, Cuadernos literarios, març, s. p.

- (1946c) «3er. poema romántico», Cuadernos literarios, abril-maig, s. p.

(1946d) «Poema» [ «Así, / con las horas hundiéndose en mis ojos... »], Cuadernos literarios, abril-maig, p. 4.

(1946d) «Poema del suburbio», signat amb el pseudònim Jorge F. March, Cuadernos literarios, abril-maig, p. 8.

REVISTA VALENCIANA DE FILOLOGIA / I (20I7) p. I99-222

SALVADOR ORTELLS MIRALLES

Les autotraduccions poètiques al castellà de Joan Fuster ('Verbo', 1946-1949) / 22 I 
(1946f) «Dos canciones inacabadas» [«Desde mi rincón el cielo esparce...», «Qué corazón tuyo, qué silencio...»], Verbo. Cuadernos literarios, agost, s. p.

(1946g) «Orilla de este amor», Verbo. Cuadernos literarios, agost, s. p.

- (1946h) «Oda al Mediterráneo», Verbo. Cuadernos literarios, octubre-novembre, s. p.

(1946i) «Poemas en la Navidad del Señor» [ "Camino de Belén», «Belén de veras»,

«Nochebuena corriente»], Verbo. Cuadernos literarios, desembre, p. 9.

- (1947a) «Presencia de la Muerte», Verbo. Cuadernos literarios, gener-febrer, p. 14.

- (1947b): [Carta mecanoscrita de Joan Fuster a Carles Salvador del 26 de setembre de 1947], Centre de Documentació Joan Fuster, AJFO.

_- (1948a) «Tres poemes» [ «A Sant Francesc d'Assís, en llegir el Càntic de les Criatures», «L'olivera», «Elegia íntima», amb versions en castellà signades amb el pseudònim V. T. M.], Verbo. Cuadernos literarios, abril-maig, p. 14.

(1948b) «(Conato de imprecación)», Verbo. Cuadernos literarios, novembredesembre, p. 10.

(1949) «Dos poemes», [«Impressió de tardor», «Cançó tranquil·la», amb versions en castellà], Verbo. Cuadernos literarios, 15, març-abril, pp. 16-17.

- (2003) De viva veu, a cura d'Isidre Crespo, Catarroja / Barcelona / Palma, Afers.

- (2006): Correspondència 10. Xavier Casp, Miquel Adlert, Santiago Bru i Vidal, $2 a$ part, a cura de Josep Ballester, València, Càtedra Joan Fuster de la Universitat de València / Tres i Quatre.

Furió, A. (1994) Àlbum Fuster, València, IVEI / Alfons el Magnànim.

Furió, A.; PALÀcios, J. (2002) «Apèndix. Notes explicatives i materials complementaris», dins Joan Fuster: Obra completa. Volum primer. Poesia, Aforismes, Diari, Vinyetes $i$ Dibuixos, Barcelona, Edicions 62 / Universitat de València, p. 939-997.

Grutman, R. (2009) «La autotraducción en la galaxia de las lenguas», Quaderns: revista de traducció, 16, 123-134.

(2013): «Beckett and Beyond: Putting Self-Translation in Perspective», Orbis Litterarum 68:3, p. 188-206.

Pérez Montaner, J. (1991) «Els primers escrits de Joan Fuster», Canelobre, 22, p. 63-70.

(1992) «Joan Fuster i l'aventura literària de Verbo», dins Miscel-lània Joan Fuster, v, Barcelona, Publicacions de l'Abadia del Montserrat, p. 259-281.

Pérez Moragón, F. (2014) «Introducció», dins Joan Fuster, Les idees religioses i l'existencialisme en el teatre modern. La bona nova a Maria, València, Denes, p. 8-58.

Recuenco, M. (2011) «Más allá de la traducción: la autotraducción», Trans. Revista de traductología, 15, p. 193-208.

REVISTA VALENCIANA DE FILOLOGIA / I (20I7) p. I99-222

SALVADOR ORTELLS MIRALLES

Les autotraduccions poètiques al castellà de Joan Fuster ('Verbo', 1946-1949) / 222 